\title{
Real-Time Early Warning and Early Prevention System to Avoid System Blackouts
}

\author{
Jóhannsson, Hjörtur
}

Published in:

Procedings of the 2018 IEEE PES General Meeting

Link to article, DOI:

10.1109/PESGM.2018.8585534

Publication date:

2018

Document Version

Peer reviewed version

Link back to DTU Orbit

Citation (APA):

Jóhannsson, H. (2018). Real-Time Early Warning and Early Prevention System to Avoid System Blackouts. In Procedings of the 2018 IEEE PES General Meeting IEEE. https://doi.org/10.1109/PESGM.2018.8585534

\section{General rights}

Copyright and moral rights for the publications made accessible in the public portal are retained by the authors and/or other copyright owners and it is a condition of accessing publications that users recognise and abide by the legal requirements associated with these rights.

- Users may download and print one copy of any publication from the public portal for the purpose of private study or research.

- You may not further distribute the material or use it for any profit-making activity or commercial gain

- You may freely distribute the URL identifying the publication in the public portal

If you believe that this document breaches copyright please contact us providing details, and we will remove access to the work immediately and investigate your claim. 


\title{
Real-Time Early Warning and Early Prevention System to Avoid System Blackouts
}

\author{
H. Jóhannsson Member, IEEE
}

\begin{abstract}
This paper presents a real-time early warning and early prevention (EWEP) system which objective is to avoid the occurrence of large scale system blackouts. The EWEP is obtained by combining a state-of-the-art methods for online stability assessment and for identifying effective counteractions into a single operational solution. The EWEP system was implemented on state-of-the-art software platform for applications of wide-area data. The EWEP system's performance was tested on synthetic wide-area measurement snapshots obtained by accurate time domain simulation of the 2003 blackout in Denmark and Sweden. The test results show that the system could automatically provide both an early warning for the blackout and efficiently determine effective countermeasures that would have avoided the blackout from occurring.
\end{abstract}

\section{INTRODUCTION}

Stable and secure supply of electric energy is of fundamental importance for welfare and growth in any modern society. System blackouts are a strong reminder of how dependent the modern society is on secure and stable operation of electric power systems. Considering a future systems scenario where high share of production is based on renewable energy sources (RES), it is foreseen that the fluctuating nature of RES will affect the systems' dynamic behavior. The altered dynamics are likely to cause existing offline and time consuming approaches, today used to ensure secure operation, to become insufficient. Hence, real-time approaches for operational awareness will be needed in future highly RES based systems.

Resent research has begun to address the challenge of ensuring system security in real-time. In [1] a method is presented for real-time assessment of aperiodic small-signal rotor angle (ASSRA) stability, based on algebraically derived expressions for critical stability boundaries [2] which laid the foundation for assessment of large systems in matter of milliseconds [3]. Online sensitivity based voltage stability assessment was presented in [4-5] while extensions to Thevenin impedance based assessment were presented in [6-8]. New approach for static security assessment in real-time is reported in [9-10]. Two different approaches for identifying effective countermeasures against ASSRA stability problems were presented in [1112]. In [13], approach for finding countermeasures to avoid activation of over-excitation limiters is presented.

This paper presents a real-time early warning and prevention (EWEP) system that extends previous research within real-time stability assessment and automatic determination of countermeasures by implementing and combining them into a single operational solution. For this purpose a dedicated SWplatform for test and implementation of applications of widearea data [14-15] is exploited. The proposed EWEP system is tested on a realistic blackout scenario, obtained by detailed simulation of the 2003 Blackout in Denmark and Sweden.
The paper is structured as follows: section II covers background theory for the real-time stability assessment and the countermeasure methods used for obtaining early warning and early prevention, section III describes the implementation and setup of the EWEP system, section IV covers details of the large-scale blackout test scenario, section VI presents test results and the paper is concluded in section VII.

\section{Methods Providing EARLY WARNing AND EARLY PREVENTION FOR INSTABILITY}

\section{A. The Early Warning Method}

The early warning method deployed in the following and described in [1], exploits online system snapshots (from synchronphasors or state estimator) to quickly determine the generators' margin in respect to ASSRA instability. Due to algebraically derived expressions for ASSRA stability boundary [2], assessment in linear time is enabled [3]. For the assessment of each generator $G_{i}$ in the system, only two system variables need to be determined; the complex Thevenin impedance $\bar{Z}_{t h}$ seen from the generator's node of constant steady-state voltage magnitude and its complex injection impedance $\bar{Z}_{i n j}$ seen from the same node determined by the ratio between the complex voltage and injected generator current. To preserve ASSRA stability, each generator $G_{i}$ must satisfy [1]:

$$
Z_{i n j} \geq \frac{-Z_{t h} \sin \theta}{\sin \phi}
$$

Where $\bar{Z}_{t h}=Z_{t h} \angle \phi$ and $\bar{Z}_{i n j}=Z_{i n j} \angle \theta$. Violation of (1) describes the condition where a small change in the generator's rotor angle will reduce the generators active steady-state power output instead of increasing it. This results in an imbalance between the generator's mechanical and electrical torque, resulting in small but gradually increasing rotor acceleration leading to loss of synchronism characterized by sharp collapse in system voltages. It can take from 10 seconds up to few minutes following disturbance for ASSRA instability to unfold.

An active power percentage margin $\% \Delta P_{i n j}$ to the stability boundaries reflected in (2) can be expressed as [1]:

$$
\% \Delta P_{i n j}=\frac{\cos \left(\delta+\phi_{t h}\right)+1}{1+\left|\frac{\bar{Z}_{i n j}}{\bar{Z}_{t h}+\bar{Z}_{i n j}}\right| \cos \left(\phi_{t h}\right)} \cdot 100 \% .
$$

The above margins describe how much the generator's active power injection can be increased before (1) is violated. Here $\delta=\arg \left(\bar{Z}_{i n j} /\left(\bar{Z}_{i n j}+\bar{Z}_{t h}\right)\right)$ represents the voltage phase angle at generator's node of constant voltage when the Thevenin voltage is used as reference. The above expression provides a convenient measure of the generators' distance-to-instability, and is used as an early warning indicator in the following. 


\section{B. The Early Prevention Method}

The early prevention method deployed in the EWEP system is based on approach from [11] which determines remedial actions by exploiting algebraically derived expressions from [2]. The determined countermeasures are in the form of setpoints adjustment of selected generators' output.

The method's objective is to ensure that the margin of a critical generator to ASSRA instability does not go below certain minimum. For that purpose, two different margins are defined: trigger margin which determines when the countermeasures should at latest be applied, and safety margin at which the generator should be operating after the countermeasure.

In case that the margin of a generator goes below the trigger margin, generator's output has to be reduced to bring the generator's margin above the safety margin. The desired safety margin $m_{s a f}$ is expressed as a percentage of the generator's maximum power injection. Utilizing expressions for curves of constant voltage magnitude and phase angle injection impedance plane from [2], the generator's voltage angle when operating at safety margin $\delta^{*}$ can be determined as [11]:

$$
\delta^{*}=\arccos \left(\frac{m_{s a f}}{100 \%}\left(1+\frac{V}{E_{t h}} \cos \phi_{t h}\right)-1\right)-\phi_{t h}
$$

Here is $V$ the generator's voltage at its node of constant voltage magnitude, and $E_{t h}=V\left|\bar{Z}_{i n j}+\bar{Z}_{t h}\right| / Z_{i n j}$ is the corresponding Thevenin voltage magnitude. With $\delta^{*}$ known, the needed change in the critical generator's output $\Delta P_{c r}$ becomes:

$$
\Delta P=\left(\frac{E_{t h} V}{Z_{t h}}\right) \cdot\left(\cos \left(\delta+\phi_{t h}\right)-\cos \left(\delta^{*}+\phi_{t h}\right)\right)
$$

Knowing the critical generator's $\Delta P_{c r}$, the other generators participating in the dispatch solution can be determined. The following procedure is suggested to find generators that should increase their production to counteract the reduction from the critical generator $G_{c r}$.

1) Rank all of the $N$ generators in list according to shortest electrical distance [16] to $G_{c r}$ and determine their active power reserve $\Delta P_{i}$, without exceeding ASSRAS safety margin or $G_{i}$ 's thermal limit.

2) For every generator $G_{i}, i \in 1 \ldots N$ in the sorted list, do:

a) mark in the list if $G_{i}$ 's available $\Delta P_{i}$ is greater or equal to $1 / 1,1 / 2,1 / 3$ or $1 / 4$ of the needed $\Delta P_{c r}$

b) Inspect the list from $G_{1} \ldots G_{i}$ for a solution with $1,2,3$ or 4 generators. If a solution is found, the search is stopped.

The above procedure prioritizes solutions consisting of 2-4 generators relatively close to $G_{c r}$ over a solution with a single generator relatively far away.

\section{SySTEM DESIGN AND IMPLEMENTATION}

Figure 1 illustrates the EWEP system deployed in this paper. The system consists of SW-platform for application of wide-area data [14-15] and three individual applications containing implementation of the previously described EWEP methods, and a supervisory and visualization application. The SW-platform obtains measurement snapshots from the external system (represented by offline PSS/E simulations in this paper) and makes them available to the individual applications.

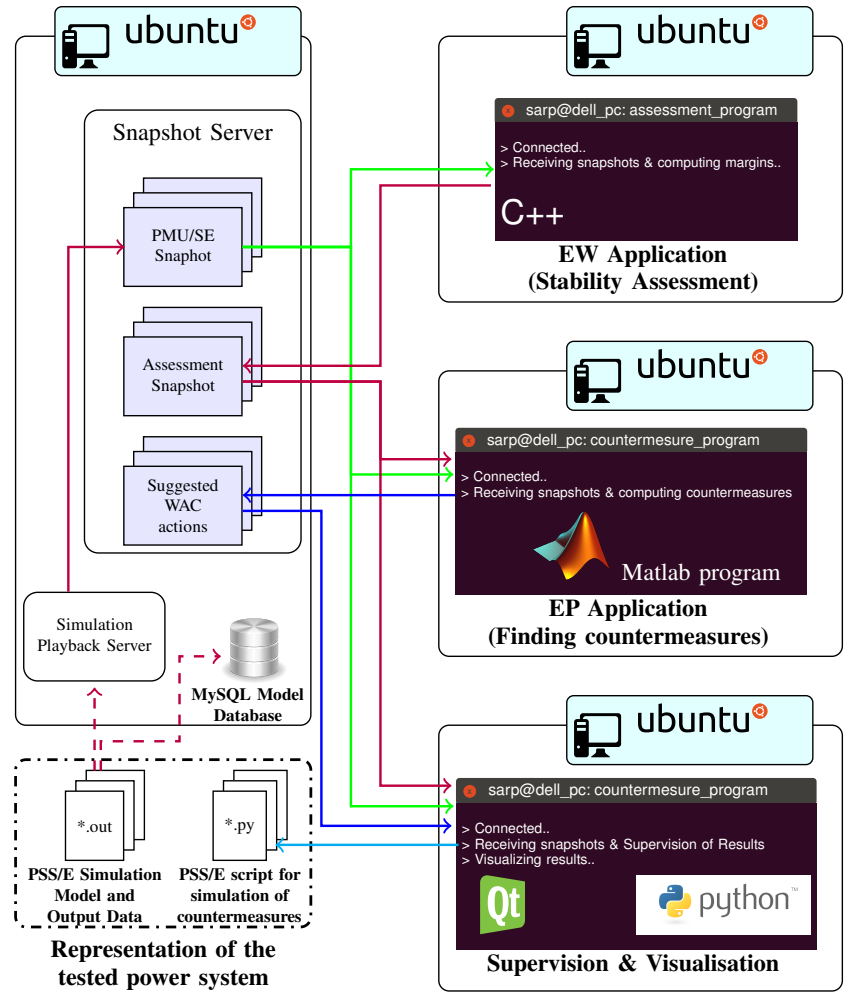

Fig. 1. Illustration of highly distributed EWEP system setup deployed in this paper. The wide-area application SW-platform reads in measurements from the external system (represented by offline PSS/E results in this case) and provides the external applications access to the measurements. In future work, the offline simulations will be replaced by direct connections to SCADA systems in real power systems.

The SW-platform makes the results, computed by individual applications, available to any of the other applications that can make use of them. In the EWEP system, the results from the EW method are sent back to the SW-platform which makes them available to the EP method that uses the results to determine appropriate countermeasures. Both of the EW and EP results are communicated to the supervisory and visualization application that executes the EP when necessary.

To perform a large scale test of the EWEP system, offline PSS/E simulations of a large scale blackout are used as input to the system. To apply a countermeasure, the EWEP system produces a PSS/E simulation script file containing the details of the countermeasure and afterwards the simulation is repeated to study the countermeasure's effect.

\section{The 2003 Blackout In DENMARK AND SWEDEN}

At midday September 23rd 2003 a series of incidents occurred which eventually led to a blackout of the eastern part of Denmark and the southern part of Sweden. The blackout resulted in approximately 2.4 million persons in eastern Denmark and approximately 0.5 million persons in the southern part of Sweden being without electricity and approximately $18 G W h$ of electricity was not delivered to the customers.

The following describes the events causing the blackout and establishes a time line of events. Additionally, references to documents containing measurement data from the time of the blackout are provided. The information provided in the following is mainly gathered from the two official reports from the blackout, one in Danish [17] and the other in Swedish [18]. 


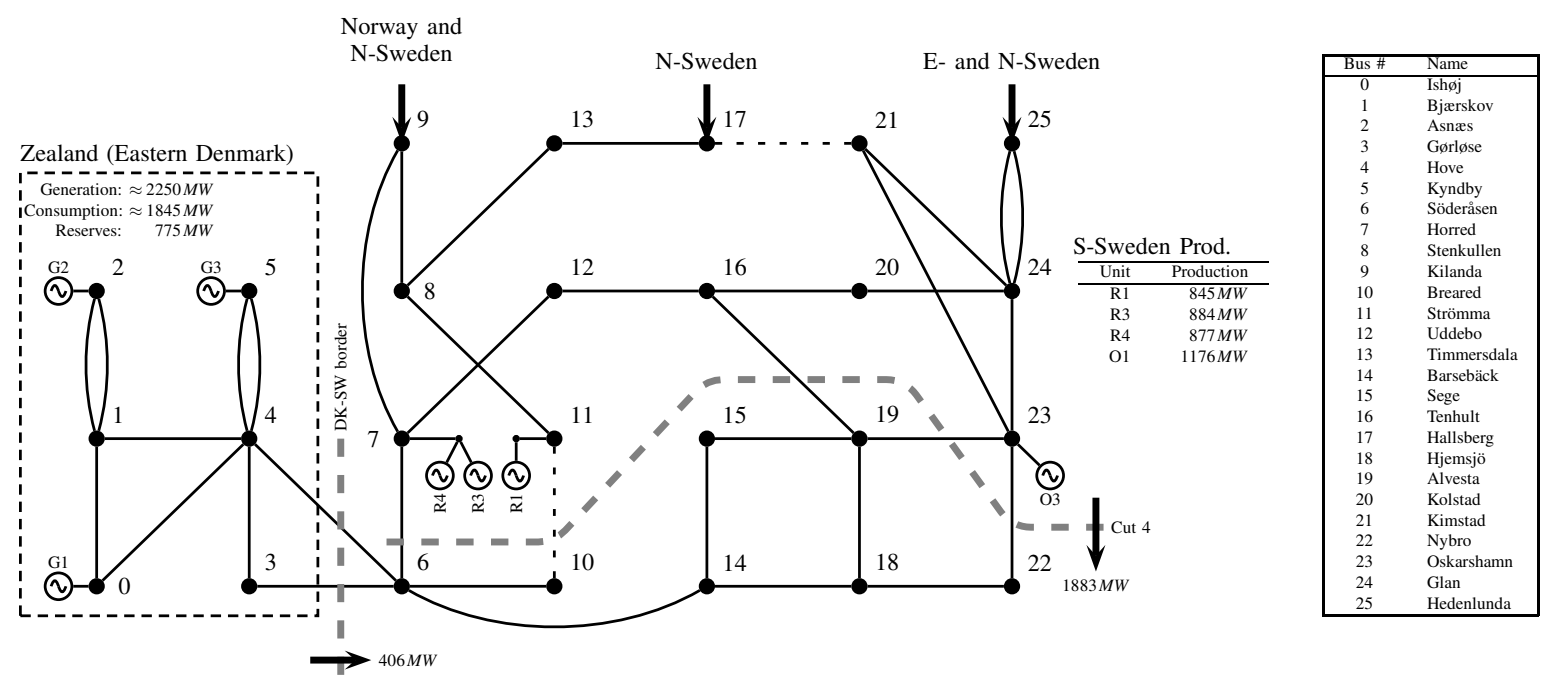

Fig. 2. The pre-fault conditions in the the $400 \mathrm{kV}$ grid in E-Denmark and S-Sweden. The generators in Zealand represent an aggregation of several generators in corresponding area, while the generators in Swedish part represent the individual generating units that where operating prior to the blackout.

\section{A. The Power System in Sweden and Denmark (2003)}

Figure 3 shows the $400 \mathrm{kV}$ grid in Sweden and E-Denmark along with the major thermal and hydro power plants. The Swedish power system was constructed such that the vast hydro power resources in north could be utilized in best way. This led to a construction of a strong transmission grid between the northern part and the central and southern part of Sweden where the main consumptions areas are located.

In Eastern Denmark (Zealand) the distance between the main power plants and the main consumption areas is short. The generation consisted of large coal-fired units (up to $650 \mathrm{MW}$ ), combined heat and power plants and a significant amount of wind power. The Swedish grid and the Zealand grid are connected through a pair of $400 \mathrm{kV}$ cables and another pair of $132 \mathrm{kV}$ cables with total cross-country capacity of $1900 \mathrm{MW}$.

\section{B. Pre-fault Conditions}

The pre-fault operating conditions were stable and well within the security constraint laid out in operational planning [19]. Some production units and overhead lines were not in operation due to seasonal maintenance. Figure 2 shows the prefault condition in the southern part of Sweden and Zealand. The figure shows which $400 \mathrm{kV}$ lines were out of order before the disturbances and the operating units in southern Sweden and information about production and consumption in the area. The available reserves in Eastern Denmark prior to the blackout were $775 \mathrm{MW}$ which was more than sufficient to cope with the loss of any single production unit in E-Denmark [17]. The Swedish system was moderately loaded prior to the disturbance with total consumption approximately $15.000 \mathrm{MW}$ nearly half of the maximum yearly consumption [18]. In SSweden, the consumption was approximately 3.000MW [17].

\section{Involved Events/Disturbances}

1) First Event - Oskarshamn: The first incident leading up to the blackout was the loss of a $1200 M W$ nuclear unit at the Oskarshamn plant (bus 23 in figure 2), due to a valve problem in the feedwater circuits. The fault led to reduction of production from $1.176 \mathrm{MW}$ to $800 \mathrm{MW}$ within $10 \mathrm{~s}$ and a full shut-down after another $10 \mathrm{~s}$.

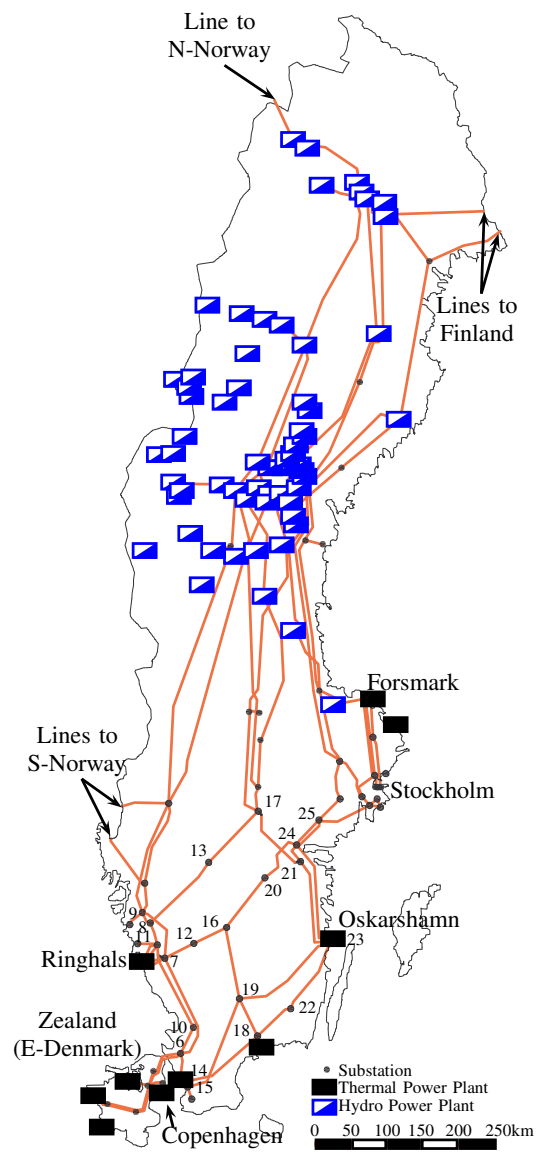

Fig. 3. The $400 \mathrm{kV}$ system in Sweden and Zealand (E-Denmark). There is strong connection between the hydro-generation in north and the consumption areas in central and southern part of Sweden. The numbered substations in the figure correspond to the bus numbers from figure 2 .

The fault was a standard contingency for which the system coped with without any subsequent interruptions. Voltages stayed within normal operating range and the frequency stabilized slightly below the normal operating limit of $49,90 \mathrm{~Hz}$ and hence, actions were initiated to raise the frequency. The fault caused a redistribution of the power flow resulting in increased flow in the E-Sweden to supply the demand in south. 


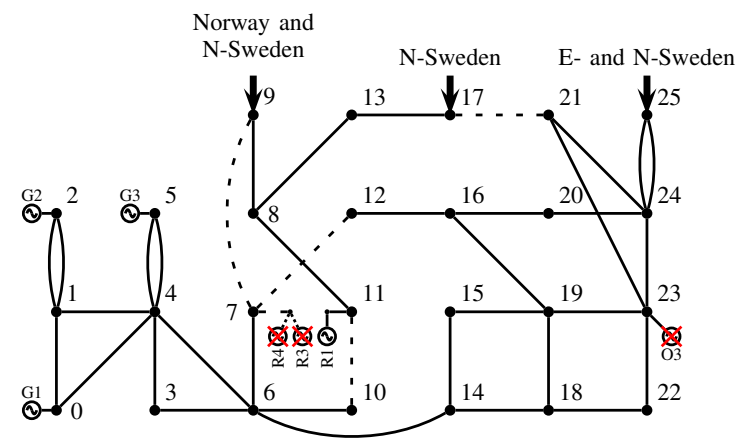

Fig. 4. The system condition after the double busbar fault in Horred (bus 7). As a consequence, practically no local production was available in the southern part of Sweden (busses 6,7,10,14-16,18-24). The power was either supplied from Denmark (through bus 6) or from North (through bus 25).

2) Second Event - Horred: Five minutes after the first event, a double busbar fault occurred in a $400 \mathrm{kV}$ substation in Horred in W-Sweden resulting in the loss of four $400 \mathrm{kV}$ lines and two $900 M W$ nuclear units at Ringhals. Figure 4 shows the condition after the fault, where it can be seen that two of the four disconnected lines made an important connection from central Sweden to S-Sweden. The loss of the two units resulted in that practically no power production was locally available in the southern part of Sweden, as the remaining Ringhals unit had no longer a connection to the South along the western coast of Sweden. To supply S-Sweden, the power had to come from Zealand through Söderåsen (bus 6) or from north, through Hedenlunda (bus 25).

The fault caused powerful oscillations and a large voltage drop in the southern part of Sweden, eventually system voltages stabilized in the range of $360 \mathrm{kV}-370 \mathrm{kV}$ in the affected area. Approximately $10 s$ after the fault, the voltage in the area began to sink first slowly then more rapidly over a period of $80 \mathrm{~s}$ until a level below $320 \mathrm{kV}$ was reached.

3) Third Event - Disconnection of $400 \mathrm{kV}$ lines: The combination of the decreasing voltage and strongly increased power flow from north to south resulted in activation of distance relays on the lines between central and S-Sweden, while the lines between Zealand and Sweden remained connected. Consequently, E-Denmark and S-Sweden experienced blackout.

TABLE I

TIME LINE OF EVENTS WHICH CAUSED THE BLACKOUT IN SWEDEN AND DENMARK ON THE SEPTEMBER 23RD, 2003.

\footnotetext{
$t=0 s \quad$ Valve fault at Oskarshamn (O3 at bus 23). The production is reduced from $1176 M W$ to $800 M W$ within $10 s$.

$t=10 \mathrm{~s} \quad$ The fault is not cleared and the generator ( $\mathrm{O} 3$ at bus 23) must be shut down. The production is reduced from $800 \mathrm{MW}$ to $0 \mathrm{MW}$ over a period of $10 \mathrm{~s}$.

$t=20 s^{+}$Reserves in Sweden, Norway, Finland and Jutland are activated. The total increase in imported power is $684 \mathrm{MW}$. The import from Zealand is increased by $81 M W$.

$t=301 s \quad$ Double busbar fault in Horred - two blocks at Ringhals (R3 and R4) and two $400 \mathrm{kV}$ lines (between busses 7 and 9 and between 7 and 12) are disconnected from the net. A $1761 \mathrm{MW}$ production is lost.

$t=301 s^{+}$A DC-link to Jutland is disconnected - 250MW import is lost.

$t=301 \mathrm{~s}^{+}$The import from Finland and Norway gradually increases by $870 \mathrm{MW}$

$t=321 s^{+}$Tap-changers begin gradually regulate the distribution voltage in the affected area which causes gradual increase in the consumption.

$t=394 \mathrm{~s} \quad$ Distance relays on eight $400 \mathrm{kV}$ lines between central and S-Sweden trip

$t=394 s \quad$ Blackout occurs eastern Denmark and the Southern part of Sweden.
}

\section{Time line of Events}

Table I shows the time line of the involved events relevant for successful time domain simulation of the blackout.

\section{BlaCKOUT SimUlation AND VERIFICATION}

The PSS/E simulation model consisted of a detailed representation of the Zealand system including all busses from $400 \mathrm{kV}$ to $50 \mathrm{kV}$ and a simplified representation of the remaining Scandinavian grid, where S-Sweden was represented in greater details than remaining parts. The simulation model contained 352 busses, 540 branches and 314 generators.

The simulation was carried out by applying the disturbances described in table I. Figure 5 shows a comparison between the simulated frequency and the actual measurements from the blackout. The strong similarity between the responses indicate that the simulation captured the right instability mechanism.

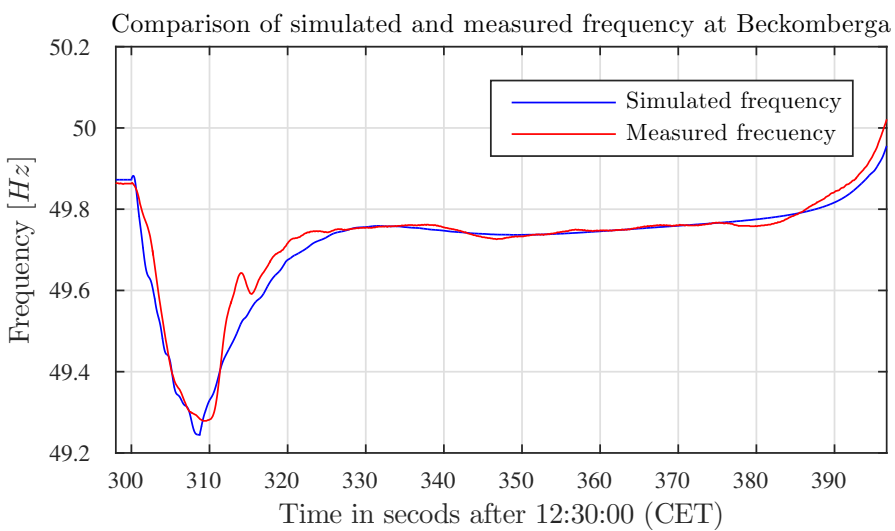

Fig. 5. Simulated results of system frequency held against measured values of the frequency from the blackout.

\section{TEST OF THE EWEP SYSTEM}

The first test studied which early warnings (EW) the EWEP system would produce for the simulated blackout scenario. Figure 6 shows simulated bus voltage at the DK-SW connection, where the occurrence of the produced EWs are annotated. The EWEP indicated 72 seconds before the blackout, that a $74 M V A$ machine $\left(G_{A}\right)$ had a stability margin lower than $0.5 \%$ and 61 seconds before the blackout the margin of a $310 M V A$ machine $\left(G_{B}\right)$ went below $1.0 \%$. Eventually, both of the machines crossed the stability boundary resulting in their loss of synchronism and rapid collapse in voltage as evident from figure 6 . The results confirm the ability of the EWEP system to provide EWs and to pinpoint the critical generators.

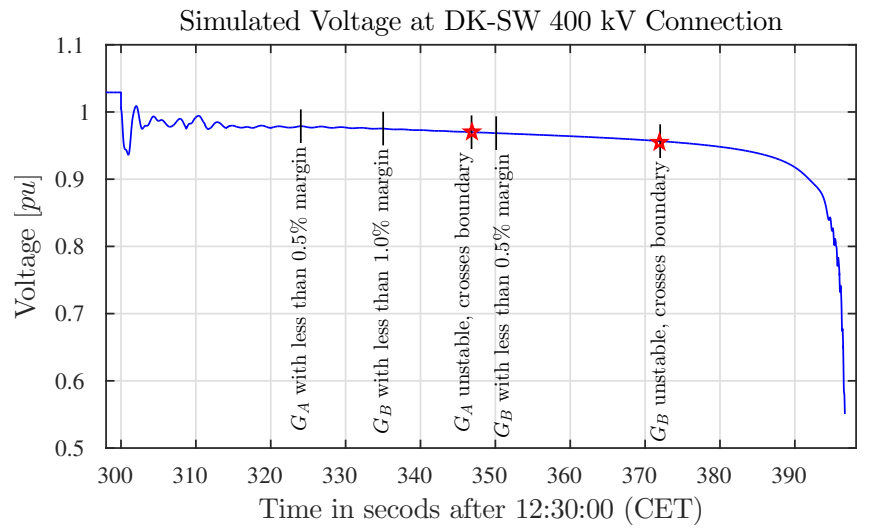

Fig. 6. Overview of the EW indicators provided by the EWEP system when the simulated blackout is used as input. 
TABLE II

OVERVIEW OF THE EARLY WARNINGS (EW) AND EARLY PREVENTIVE (EP) COUNTERMEASURES PROVIDED BY THE EWEP SYSTEM.

\begin{tabular}{|l|l|}
\hline time & Warning \& proposed countermeasures \\
\hline $322 s$ & EW: Margin for $G_{A} \leq 0.5 \%$ \\
$327 s$ & EW: $G_{A}$ below trigger margin \\
$327 s$ & EP: $G_{A}$ reduced by $2.8 M W, G_{C}$ increases by $2.8 M W$ \\
$335 s$ & EW: Margin for $G_{B} \leq 1.0 \%$ \\
$351 s$ & EW: Margin for $G_{B} \leq 0.5 \%$ \\
$358 s$ & EW: $G_{B}$ below trigger margin \\
$358 s$ & EP: $G_{B}$ reduced by $4.8 M W, G_{D}$ increases by $4.8 M W$ \\
\hline
\end{tabular}

Table II and figures 7 and 8 show the results from deploying the EWEP system described in section III. The EWEP system's trigger margin was set to $0.4 \%$ and it's safety margin at $2.0 \%$. The system applied the first countermeasure when $G_{A}$ crossed $0.4 \%$ margin at $t=327 \mathrm{~s}$ and then a second countermeasure when $G_{B}$ crossed the $0.4 \%$ margin at $t=358 \mathrm{~s}$. The size of the generators power reduction was $2.8 M \mathrm{~W}$ for $G_{A}$ and $4.8 M W$ for $G_{B}$. The voltage profiles in figure 7 show how the impending blackout was prevented by applying the two countermeasures determined by the EWEP system.

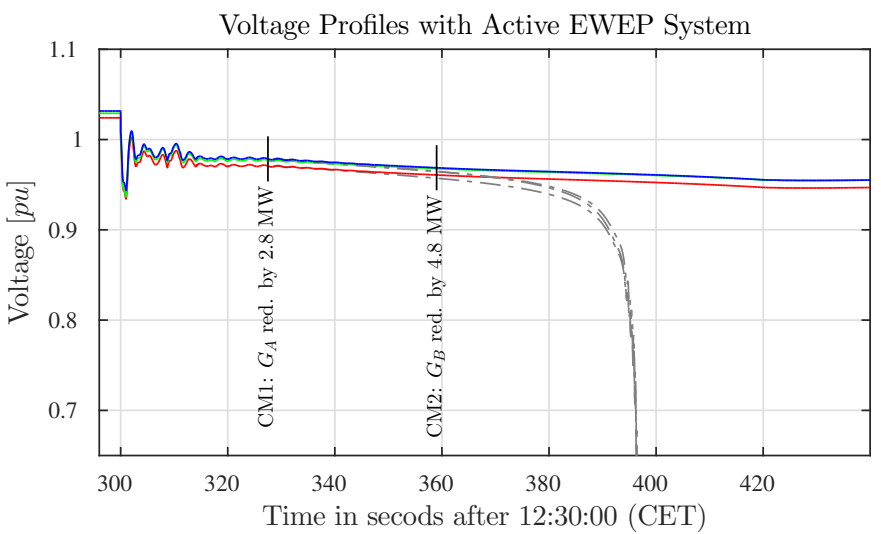

Fig. 7. Results from repeated blackout simulation, where the EWEP system applies two countermeasures. Subsequently, the system stabilizes and the impending blackout avoided. The dashed lines present the original blackout scenario, for visual comparison of the two cases.

Figure 8 shows the rotor angles of $G_{A}$ and $G_{B}$ relative to the system's average rotor angle. The figure demonstrates that the countermeasures effectively stopped the drifting of the generators' rotor angle and the subsequent loss of stability.

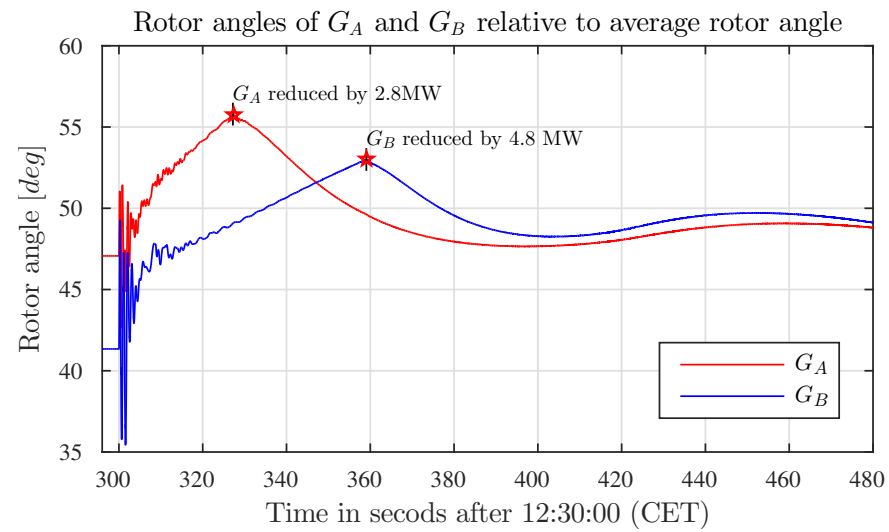

Fig. 8. Rotor angles of $G_{A}$ and $G_{B}$ plotted relative to the mean of all rotor angles in the system. The effect of EWEP system's countermeasure is visually evident as the rotor angle drift ends after the setpoint adjustments.

\section{CONCLUSION}

The paper proposed a real-time EWEP system that combines state-of-the-art methods for stability assessment and countermeasures into single operational solution. Simulations of the 2003 blackout in Sweden and Denmark were used to test the system and the results indicated that the system could have effectively avoided the blackout by applying two relatively small countermeasures. Such approaches, that in real-time provides awareness about system security and stability seem to be a promising path forward when it comes to coping with critical scenarios in future fluctuating RES based system.

\section{REFERENCES}

[1] H. Jóhannsson, A. H. Nielsen, and J. Østergaard, "Wide-Area Assessment of Aperiodic Small Signal Rotor Angle Stability in Real-Time," IEEE Trans. Power Syst., vol. 28, no. 4, pp. 4545-4557, 2013.

[2] — , "Identification of Critical Transmission Limits in Injection Impedance Plane," INT J ELEC POWER, vol. 43, no. 1, 2012.

[3] S. Sommer and H. Jóhannsson, "Real-time Thevenin Impedance Computations," in 2013 IEEE ISGT conference, Washington DC, US, 2013.

[4] M. Glavic and T. Van Cutsem, "Wide-area detection of voltage instability from synchronized phasor measurements. part i: Principle," IEEE Trans. Power Syst., vol. 24, pp. 1408-1416, August 2009.

[5] — , "Wide-area detection of voltage instability from synchronized phasor measurements. part ii: Simulation results," IEEE Trans. Power Syst., vol. 24, pp. 1417-1425, August 2009.

[6] A. Perez, H. Jóhannsson, and J. Østergaard, "Wind farms generation limits and its impact in real-time voltage stability assessment," in IEEE PowerTech 2015, Eindovhen, June 2015.

[7] — "Improved method for considering PMU's uncertainty and its effect on real-time stability assessment methods based on Thevenin equivalent," in IEEE PowerTech 2015, Eindovhen, June 2015.

[8] A. Perez et al., " Improved Thevenin equivalent methods for real-time voltage stability assessment," in Proceedings of 2016 IEEE International Energy Conference, Leauven, Belgium, October 2016.

[9] J. Møller, H. Jóhannsson, and J. Østergaard, "Contingency Assessment with Detection of Aperiodic Small-Signal Instability," in 2015 IEEE PES General Meeting, Denver, Colarado, July 2015.

[10] _ _Fast Computation of Steady State Nodal Voltages in Power System Contingency Studies," in 2014 IEEE Power Quality and Reliability Conference, Tallin, Estonia, June 2014.

[11] J. Weckesser, H. Jóhannsson, and J. Østergaard, "Real-Time Remedial Action against Aperiodic Small Signal Rotor Angle Instability," IEEE Trans. Power Syst., vol. 31, pp. 387-396, 2016.

[12] E. Dmitrova et al., "Early Prevention Method for Power System Instability," IEEE Trans. Power Syst., vol. 30, pp. 1784-1792, 2015.

[13] A. Pedersen et al., "On-line Generation and Arming of System Protection Schemes," in Proceedings of the 10th Electric Power Quality and Supply Reliability Conference, 2016.

[14] H. Morais et al., "SOSPO-SP: Secure Operation of Sustainable Power Systems Simulation Platform for Real-Time System State Evaluation and Control," IEEE Transactions on In Industrial Informatics, 2014.

[15] H. Jóhannsson et al., "SW-platform for R\&D in Applications of Synchrophasor Measurements for Wide-Area Assessment," in Cigre 2014 Grid of the Future Symposium, Houston, Texas, US, November 2014.

[16] K. Visakha, D. Thukaram, and L. Jenkins, "Transmission charges of power contracts based on relative electrical distances in open access," Electric Power Systems Research, vol. 70, no. 2, pp. 153 - 161, 2004.

[17] Elkraft System, "Strømafbrydelsen i Østdanmark og sydsvergie 23. september 2003, endelig hændelsesrapport," Tech. Rep., 2003.

[18] Svenska Kraftnät, "Elavbrottet 23 september 2003 - händelser och åtgärder," Tech. Rep. Nr 1:2003, 2003.

[19] —, "The blackout in southern sweden and eastern denmark, 23 september, 2003," Tech. Rep., 2003.

Hjörtur Jóhannsson (M'11) received the M.Sc. and PhD degrees in electrical engineering from the Technical University of Denmark (DTU), in 2007 and 2011 respectively. Currently a Senior Scientific Consultant and previously Assistant Professor at the Center of Electric Power and Energy (CEE) at DTU with primary responsibility in leading large $\mathrm{R} \& \mathrm{D}$ projects and in education of $\mathrm{PhD}$ and master students. His research interests concern the development of methods for secure and stable operation of power systems with very high share of RES based production, with special focus on real-time approaches. 